QUADERNS DE FILOSOFIA VOL. VII NÚM. 2 (2020): I I7-I 39

eISSN: 234 I-3042 DOI: I0.7203/QFIA. 7.2.I $880 \mathrm{I}$

LUCAS MISSERI

Universidad de Alicante

\title{
Zamiatin y la ética kantiana: libertad y felicidad en Nosotros
}

Zamyatin and Kantian Ethics: Freedom and Happines in We

Recibido: 6/10/2020. Aceptado: 3/12/2020

Resumen: Nosotros cumple un siglo y, a diferencia de otras distopías, no existen muchos estudios en español sobre ella. En este trabajo se analiza la perspectiva de la ética retratada en la novela y en especial el conflicto entre libertad y felicidad como una dicotomía en la cual se privilegia a la felicidad sobre la libertad. Tras analizar las referencias a Kant en la obra, se concluye que es verosímil considerar que la postura del escritor ruso se asemeja a la de la ética kantiana. Finalmente, se sostiene que la dicotomía entre libertad y felicidad es una falsa dicotomía.

\begin{abstract}
Since a century ago when it has been written, We has not been the focus of the Spanish critical attention, in contradistinction to other dystopias This work analyzes the perspective on ethics portrayed in the novel and especially the conflict between freedom and happiness as a dichotomy in which happiness is privileged over freedom. After analyzing the references to Kant in the work, it is concluded that it is plausible to consider that the position of the Russian writer is similar to that of Kantian ethics. Finally, it is argued that the dichotomy between freedom and happiness is a false dichotomy.
\end{abstract}

Palabras clave: distopía, pensamiento utópico, crítica social, literatura rusa, Kant. Keywords: dystopia, utopian thought, social critique, Russian literature, Kant. 


\section{INTRODUCCIÓN}

$\mathrm{E}$ L INGENIERO NAVAL Y ESCRITOR RUSO Evgeni Zamiatin, 1884-1937, cuyo nombre completo es Евгений Иванович Замятин, a veces transcrito como Yevgueni Ivánovich Zamyatin para ser más fiel a su pronunciación, escribió una de las distopías más influyentes del siglo xx: Nosotros. Esta obra fue compuesta en ruso entre 1920 y $1921,{ }^{1}$ es decir, exactamente un siglo antes de este texto. Si bien la misma ha sido notoriamente influyente para las futuras visiones de la distopía, especialmente por su influjo en novelas como Un mundo feliz de A. Huxley, de 1932, y 1984 de G. Orwell, de 1949, su análisis en español ha sido escaso. Estudios de la recepción de Zamiatin en el mundo de habla hispana explican esto por dos razones: por un lado, la tardía traducción a nuestro idioma, dado que la primera es de 1970, y, por otro lado, el hecho de que el género de ciencia ficción, al que está asociado, solo recientemente fue ganando el prestigio suficiente como para obtener atención académica (cf. Kiselova y Marín 2O I 5 ).

En ocasión del centenario de Nosotros, se considera que vale la pena releer su prosa vanguardista y desentrañar los problemas filosóficos que encierra la trama de la novela que le valió el ser considerado un traidor a la causa revolucionaria por sus compatriotas (VorOnsky, I988 [i 922] y SHKLOVsky I 988 [I 927]). Si bien hay varias cuestiones que pueden abordarse, aquí se ha optado por los problemas de filosofía moral desde una doble perspectiva: la que es atribuible al Estado distópico descrito en la novela y la que se puede atribuir al propio Zamiatin, en tanto que autor de Nosotros. La perspectiva interna procura dar cuenta de qué visión de la ética normativa aparece en las anotaciones del protagonista de la obra: D-503. Mientras que la perspectiva externa busca responder a cómo dicha visión puede extrapolarse no solo para reconstruir el pensamiento de Zamiatin, sino también para pensar nuestro tiempo y nuestros desafíos, en un mundo que en muchas ocasiones se nos presenta como distópico.

De los desafíos que surgen de esa doble lectura, el más interesante para la filosofía práctica probablemente sea el problema del conflicto entre la felicidad y la libertad, que ocupa un lugar central en toda la novela. Para abordarlo se ha dividido este artículo en tres secciones: la primera se sitúa en el marco de los estudios de la utopía y ofrece una definición guía de qué se entiende por distopía y qué rol ha jugado Nosotros en la historia de este subgénero de la literatura utópica. En la segunda sección, se aborda cómo se manifiesta

\footnotetext{
${ }^{1}$ Hay controversia en torno a la fecha exacta de composición de Nosotros. Kern (1988, 9) sostiene que Zamiatin terminó la novela en 1920 y la envió a la editorial Grzhebin de Berlín en 1921. Otros, como Kiselova y Marín (20 I 5, 168), sostienen que la concluyó en 1921.
} 
expresamente el problema en la trama de ficción, desde la conciencia del protagonista D-503 al armazón del Estado Único. En la tercera sección, se argumenta en favor de una posible interpretación de la opinión de Zamiatin al respecto del conflicto entre libertad y felicidad procurando defender que la postura del escritor ruso se acerca más a la de Kant, autor al que menciona tres veces en la novela.

En última instancia, lo que se busca defender con este trabajo inspirado por la relectura de Nosotros es que, si bien hay una larga tradición que contrasta libertad individual a felicidad colectiva, el opuesto tampoco es el mejor escenario posible y que, a fin de cuentas, se trata de un falso dilema. La felicidad requiere de la libertad, aunque a veces las malas decisiones o los conflictos entre la libertad de individuos puedan ser un obstáculo para alcanzar la felicidad. Pero no por ello hacen que la libertad deje de ser una condición de posibilidad para la felicidad.

\section{ZAMIATIN Y LAS DISTOPÍAS}

Un modo de pensar el concepto de distopía es como una forma particular dentro del pensamiento utópico. Si el utopismo, en general, se ocupa del ideal de sociedad, la distopía es aquella forma que se ocupa de mostrar las distintas maneras en las que ese ideal puede fallar o puede ser mal empleado adrede. Ya sea porque este se concreta y produce un resultado horroroso no previsto o porque el ideal es imposible, autofrustrante o incluso ni siquiera es perseguido de modo genuino. En este sentido la distopía puede tener una finalidad autocrítica dentro del pensamiento utópico, denunciando las limitaciones y errores de utopistas previos, pero también puede tener una finalidad precautoria, al exponer que si se siguen ciertas políticas o si se desatienden otras el resultado posible puede ser terrible. Esta forma del pensamiento utópico, al igual que su contraparte positiva (la eutopía), suele plasmarse en un artificio narrativo que lleva adelante dichas funciones a partir de la descripción de una sociedad peor que la presente. Es común que esos relatos ficcionales se proyecten en el futuro, ya sea cercano o remoto. El caso que nos interesa, Nosotros de Zamiatin, se proyecta al siglo xxx. Esto si bien permite que el autor se tome varias licencias creativas en su descripción del futuro, también le quita poder precautorio a la descripción, dado que la lejanía temporal corre el peligro de inhibir la preocupación de la generación presente por lo que ocurriría en un futuro tan remoto.

Aun cuando la distopía pueda ser concebida como el opuesto axiológico de la (e)utopía, existe una línea de continuidad entre las utopías en su sentido 
eutópico y las distopías. Ocurre porque aquello que para unos es una eutopía para otros es una distopía. ${ }^{2}$ En el estudio de Gregory Claeys dedicado a este concepto, se distingue entre distopía de ficción y distopía no-ficcional, categorías que se corresponden aproximadamente con el uso que les dieron respectivamente los primeros autores en emplear el término: Younge, al hablar de dustopia y Stuart Mill, al emplear la palabra dystopia. ${ }^{3}$ En este trabajo el foco está puesto solo en la primera, la narración ficcional de una sociedad imaginaria indeseable. Esa preferencia por la distopía de ficción no niega que gran parte del análisis pueda extenderse a valoraciones del presente como "distópico" de acuerdo a una cierta escala de valores. No obstante, eso implica una serie de contrafácticos y problemas de inconmensurabilidad axiológica que exceden las posibilidades de este trabajo. Además de esa distinción entre ficción y noficción, Claeys distingue tres formas del concepto de distopía: las distopías políticas, las distopías ambientales y las distopías tecnológicas (CLAeys 20I7, 5). Las que Claeys llama "distopías políticas" son también conocidas como distopías "clásicas o canónicas" (MoyLAN 2000, 121) y generalmente giran en torno a la tríada compuesta por Nosotros, Un mundo feliz y 1984. El influjo de Zamiatin en esas distopías "canónicas" ha sido subrayado en muchos lugares por los propios autores distópicos y los críticos literarios, véase por ejemplo Orwell (1946) y Trousson (1995). Orwell es el que lo reconoce más abiertamente en su reseña de Nosotros de 1946. En cambio, en Huxley, donde más similitudes hay, este reconocimiento no se ha hecho manifiesto. A pesar de ello es en Un mundo feliz de Huxley donde mejor se aprecia la continuidad del conflicto entre libertad y felicidad trazado por Zamiatin, pero si seguimos a Orwell el tratamiento que hace este de lo político es mucho más valioso e informado que el de Huxley. Adorno considera que la visión de Huxley implica una vuelta al conservadurismo al plantear una falsa oposición entre felicidad objetiva y subjetiva (Adorno I962, 118). En cualquier caso, los tópicos recurrentes de las distopías políticas dan cuenta de la importancia del conflicto

${ }^{2}$ Véase, por ejemplo, el intento de Wegner (1993) de interpretar a Nosotros de modo distinto al canónico en el mundo anglosajón que considera Nosotros una antiutopía. Si bien en este artículo se prefiere el término distopía, el de antiutopía tiene una carga negativa aún mayor, dado que no ataca solo a un ideal o utopía en particular, sino que apunta contra el utopismo en su conjunto. Es esa lectura la que Wegner disputa, al considerar que pueden encontrarse atisbos de esperanza en el futuro entre las anotaciones de D-503.

${ }^{3}$ El término "distopía" aparece en el poema de Lewis Henry Younge "Utopia: or, Apollo's Golden Days" [Utopía: o, los Días Dorados de Apolo], publicado en Dublín en 1747. Más precisamente aparece como "dustopia", dado que la ípsilon (Y, v) suele se transcrita en inglés como " $u$ " por su similitud fonética. En 1868, fue John Stuart Mill, quien en un discurso crítico del trato que los británicos daban a los irlandeses empleó el término "dystopia", transcribiendo la ípsilon como $y$. Para una explicación más detallada del origen del término y de sus problemas de definición, véase Claeys (2017, cap. 5). 
libertad/felicidad y los diversos modos en que este puede ser resuelto de modo negativo para el individuo.

Si Zamiatin ejerció una fuerte influencia en otros autores distópicos, él mismo fue influido por autores asociados al pensamiento utópico, tanto en sus vertientes eutópicas como distópicas, en los que el conflicto entre libertad y felicidad también está presente. Entre esas influencias se pueden contar las siguientes: Platón, Wells, Dostoievski y Jerome. De Platón (2004, 202) y de Wells (2000 [1905]) derivó el elitismo de los guardianes de Nosotros, semejantes parcialmente a los guardianes (phylakes) de la República platónica y a los samuráis wellsianos de Una utopía moderna. También de Platón, derivaría el hecho de que los poetas estén al servicio del Estado (Platón 2004, 601), como es el caso del "Instituto Estatal de Poetas y Escritores del Estado Único" (Zamiatin 2008, 107). Aunque es más probable que este se encuentre inspirado en el Glavlit, ${ }^{4}$ fundado en la URSS en 1922, del cual Nosotros cuenta con el particular privilegio de ser la primera novela censurada por ese organismo (Kern I 988, 9).

Pero las dos influencias más importantes para el tema que nos interesa aquí son las de Dostoievski y Jerome. En la obra del escritor ruso se encuentra el tratamiento del conflicto entre libertad y felicidad a favor de esta última. Específicamente en su última novela, Los hermanos Karamazov, publicada en 1880. En Dostoievski el problema se plantea en el contexto de la institución religiosa, más que en el de las instituciones políticas como en Zamiatin. Aunque la retórica de las instituciones políticas como el Estado Único, el Gran Benefactor y las Tablas de la Ley tienen un claro simbolismo religioso. De cualquier forma, algunos pasajes de la pluma de Dostoievski son especialmente sugerentes para el tema de este artículo. En el capítulo V del libro quinto, Iván Karamazov narra a su hermano Aliosha la idea para su poema "El Gran Inquisidor", historia de un cardenal casi nonagenario de la Sevilla del siglo xvi. Ese personaje tiene un monólogo con Cristo vuelto a la Tierra, a quien mantiene preso para que no perturbe la obra de la Iglesia católica. El Inquisidor describe el conocimiento del bien y del mal que viene con la libertad de elección como una "maldición" para la

\footnotetext{
${ }^{4}$ Acrónimo para las palabras rusas correspondientes a "Dirección general para la protección de los secretos de Estado".

${ }^{5}$ Con la transcripción del apellido Достоевский ocurre algo similar que con Zamiatin. El mismo ha sido transcrito como Dostoievski, Dostoyevski, Dostoevskiy, Dostoiewskij. Aquí se decidió seguir el mismo criterio que con Zamiatin, pero la excepción es que en la cita textual se sigue la versión germanizada, Dostoiewski, que es la de la edición que se empleó para citar Los hermanos Karamazov. Lo mismo ocurre con Zamiatin, cuando la cita es de la transcripción española o del original ruso he conservado Zamiatin, mientras que cuando es de la inglesa aparece como Zamyatin.
} 
humanidad (DostoiewsKi 5 I 930, 233) y “[r]eclama para sí y para la Iglesia el mérito de haber aniquilado por fin la libertad para dar de este modo la felicidad a los hombres" (226). Esto porque "[...] nada ha habido jamás tan insoportable para el individuo y la sociedad como la libertad [...] La ciencia no les proporcionará un trozo de pan, mientras sean libres. Y al fin, depositarán su libertad a nuestros pies, diciéndonos: 'Tomadnos por esclavos, pero sustentadnos"' (227). Algunos críticos rusos vieron en las obras de Dostoievski un vínculo directo con la obra de Kant en lo concerniente al tema de la libertad y la felicidad, ${ }^{6}$ vínculo que en este trabajo consideramos replicado en Nosotros.

Finalmente, "La nueva Utopía" del escritor inglés Jerome K. Jerome es, según algunos críticos como Shklovsky ( I 988, 49), la fuente de algunas de las ideas que aparecen en Nosotros. Jerome describe un futuro en el que el socialismo ha triunfado y la vida parece más distópica que utópica, más una pesadilla que el sueño añorado de la igualdad. Esto porque más que de igualdad la "nueva Utopía" de Jerome habla de igualación hacia abajo, de homogeneización forzada. Es probable que Zamiatin tomase de esta breve obra la idea de nominar a las personas con números y los uniformes grises (Jerome 20 i 8). Recuérdese que el escritor ruso pasó un tiempo en Inglaterra, donde analizó críticamente la cultura local, de cuya literatura era un avezado lector y admirador como dan cuenta su biografía y sus obras. ${ }^{7}$

\section{2. ÉTICA, LIBERTAD Y FELICIDAD EN LAS ANOTACIONES DE D-503}

La novela está narrada en primera persona por D-503, un ingeniero - como Zamiatin - que está a cargo de la construcción de la nave Integral, que surcará el espacio para expandir las ideas del Estado Único más allá de la Tierra. Esto insta a D-503 a volcar en anotaciones sus pensamientos diarios, con la esperanza de que los puedan leer extraterrestres, que él imagina en un estado previo de civilización. Para él, los venusinos y uranitas que visitará la Integral estarán tan atrasados como los terrícolas del siglo xx, por lo cual se

${ }^{6}$ Mijaíl Málishev (I997, 334) menciona, entre los primeros en advertir el vínculo entre Dostoievski y Kant, al escritor Dmitri S. Merezhkovski, 1866-1941, y al filósofo y traductor Yakov E. Golosovker, 1880-1913. Merezhkovski menciona a Kant en su Dostoievski y Golosovker en su Dostoievski y Kant.

${ }^{7}$ Para la visión de Zamiatin como un ruso anglófilo, véase Curtis (2013). Para la crítica de la sociedad inglesa véase, Островитяне [Los isleños] de 1917 (Zaмiatin 2003A, 389-441). Para una comparación entre Rusia e Inglaterra posterior a su novela distópica, véase por ejemplo La pulga de 1926, adaptación teatral que hizo Zamiatin de una obra de Leskov, en traducción espańola (ZамiATın i $968,58-115)$ y en ruso (2004, 309-57). 
esfuerza en explicar los avances realizados por la Tierra en su tiempo, el que casi con seguridad sería el siglo xxx. ${ }^{8}$ Eso permite que el protagonista se dirija a los contemporáneos de Zamiatin, aun cuando la acción transcurra diez siglos en el futuro.

En el presente de D-503, ya ha pasado una guerra que duró doscientos años y tras ella la mayoría de la población vive en ciudades amuralladas que conforman el Estado Único. En ese Estado hiperracional y con rasgos totalitarios no hay yoes, sino un único "nosotros". Esto se consigue igualando al máximo posible todos los aspectos de la vida cotidiana. Los ciudadanos llevan por nombre una letra y un número y de los nombres de los personajes se deduce que los hombres llevan letras consonantes y números impares por ej. D-503 y R-13 - y las mujeres vocales y números pares - por ej. O-90 y I-330 - Tras la Guerra de los Doscientos Años, además de erigir el Muro Verde que separa la ciudad y todo lo mecánico de la vegetación y todo lo natural, se establecieron las Tablas de la Ley, que entre otras cosas determinan con extremada precisión qué debe hacer cada "número" en cada momento. La única excepción la constituyen las dos horas diarias que los números pueden destinar a paseos o a relaciones sexuales. Sin embargo, estas últimas también están reguladas por unos cupones rosados. Como parte de la igualdad homogeneizante, cada número debería poder tener relaciones sexuales con cualquier otro, por eso basta con solicitar el correspondiente cupón rosa para tener relaciones con otro número. Asimismo, las casas de todos son paralelepípedos transparentes en los que todos los vecinos pueden ver lo que se hace en su interior en todo momento, excepto cuando los números están haciendo uso del cupón rosado, momento en el cual deben correr las cortinas.

D-503 aprovecha una de sus dos horas libres para escribir en su manuscrito. Allí se da un proceso de autodescubrimiento en el cual pasa de tener esperanzas en que el Estado Único determine también qué hacer en las dos horas de ocio a desear la destrucción de ese Estado. Esa metamorfosis de número obediente a revolucionario se ve estimulada por su relación con I-330, miembro de los Mefi, grupo revolucionario que atenta contra el

${ }^{8}$ El siglo se deduce del elogio que hace el personaje D-503 de la obra de Frederick W. Taylor: "sin duda ese Taylor era el más genial de los antiguos" (Zamiatin 2008, 68). Así como Huxley medirá en Un mundo feliz el tiempo antes y después de Henry Ford, Zamiatin usa de referencia a Taylor y dice que pasaron mil ańos desde los avances realizados por el pensador inglés, de lo que se deduce que hablamos del siglo xxx. De esta misma opinión son Kern (I988) y Trousson (I995). Si bien para Orwell (I946) las distopías de Zamiatin y Huxley transcurren en el mismo siglo xxvı, lo más probable es que sea un error debido a una lectura rápida o incompleta. 
Día de la Unanimidad - pseudovotación anual en la que se reelige el líder totalitario, el Benefactor - y que planea hacerse con la nave Integral, para liberarse del yugo del Estado Único. Los mefi, probablemente abreviatura de "mefistofélicos", 9 se oponen a la hiperregulación y al maquinismo del Estado Único. Ellos conviven con salvajes residentes más allá del muro, valoran costumbres prohibidas como el alcohol y el tabaquismo y construcciones opacas como la "casa antigua", en la que D-503 e I-330 se ven varias veces.

La novela narra la relación turbulenta entre esos personajes y otros personajes secundarios como O-90 y R-13, que además de conformar una ménage à trois con D-503 son para él como su "familia". La mefi I-330 le genera al protagonista una pasión tan fuerte que va más allá del adoctrinamiento en el que nació. Empieza a tener deseos, celos y hasta sueños. Se cuestiona dogmas básicos del Estado Único y de su existencia. Se desdobla más allá del "nosotros" que caracteriza a su pueblo en dos yoes: uno que sigue reconociendo las reglas de su Estado y que es consciente de sus delitos y otro, que él llama su yo-peludo, su parte primitiva, salvaje, que se ve atraído de modo animal por I-330. Esas contradicciones son nuevas para D-503 y es forzado a ver un médico, el cual le diagnostica "alma". Tener alma implica tener fantasías, deseos propios y en el Estado Único solo el Estado tiene derechos y los números tienen deberes. Allí, donde un yo disienta del "nosotros" será condenado a la máquina del Benefactor, una guillotina futurista que transforma a los seres humanos en un charco de agua, aniquilándolos por medio de la fisión nuclear.

D-503 no es el único con "fantasías" y el Estado Único responde a esa desviación colectiva ofreciendo una operación que anulará la parte del cerebro responsable de esa función. De este modo, los números podrán ser tan racionales y obedientes como la autoridad precisa. Poco a poco, los ciudadanos se van operando, hasta que se establece un día en el que la operación se hace obligatoria para todos. Esa misma jornada, D-503 es curado de su alma y la novela concluye con su relato ascético y racional acerca de cómo su antigua amada, I-330, es torturada en la cámara de gas para luego ser llevada a la máquina que la aniquilará.

Tras este resumen de la trama general de la novela, se pueden resaltar los aspectos específicos vinculados a la ética y particularmente al conflicto entre libertad y felicidad, tema recurrente en el manuscrito de D-503.

\footnotetext{
${ }^{9}$ En la obra hay muchas referencias al cristianismo, Adán, Eva, Jesús, Josué, etc., sin embargo, es probable que la elección de este nombre se deba a que el propio Zamiatin se consideraba un mefistofélico a ojos de la ortodoxia soviética. Tal como se sigue de su carta a Stalin de 1931: "[...] la crítica ha hecho de mí el diablo de la literatura soviética" (Zamiatin 2008, 9).
} 


\section{1 Ética vs. Ciencia}

La primera aproximación al conflicto libertad y felicidad que permite comprender el lugar de la ética en el Estado Único viene dada por la contraposición entre la ética y la ciencia. La ética presupone la libertad como condición de posibilidad, sin libertad no se puede considerar que las acciones de los individuos sean morales, sino más bien el resultado de la causalidad, de condicionamientos previos y, por tanto, no merecen ni reproche ni alabanza. Incluso Kant, al mostrar las dificultades de dar una prueba última de la libertad — por su carácter nouménico-, considera que esta tiene que ser presupuesta para hablar de ética en algún sentido no trivial.

Para D-503, esta visión de la ética es primitiva, incivil y salvaje, pues depende de la libertad humana, y la libertad humana, más que garantizar la felicidad, puede obstaculizarla. Por lo cual considera que a la ética hay que contraponer la ciencia, el determinismo, la ausencia de libertad y, por tanto, la posibilidad de la dicha. Es en este sentido que se justifican el Estado Único, el rol del Benefactor y la importancia de la Tabla de las Leyes. Los tres aspectos buscan, por medio de la anulación de la libertad, garantizar la felicidad sobre la base de la siguiente fórmula, expuesta en la anotación 5 (ZAMiATin 2008, 56):

$$
\text { Felicidad }=\text { Bienestar }^{10} / \text { Envidia }
$$

Al quitar todo rastro de individualidad y libertad, la envidia tiende a cero, casi nadie puede envidiar lo que tiene el otro, puesto que todos tienen lo mismo o pueden acceder a lo mismo. Y si la envidia tiende a cero, entonces la dicha debería tender al infinito. Esa es la fórmula de la felicidad del Estado Único. No obstante, hay dos notas a tener en cuenta. Por un lado, Zamiatin parece decir que la envidia es igual a cero, lo cual ofrece un problema matemático —el de dividir por cero- y no la proyección al infinito de la dicha. Por otro lado, el Benefactor es el único que no ocupa un rol idéntico a los demás, está exceptuado de la homogeneización y el control constante. Sin embargo, como en otras distopías ${ }^{11}$ hay algo de mecánico en su descripción. El mismo es descrito por momentos como una máquina gigante más que como

${ }^{10}$ El término ruso para el numerador еs блаженство que también puede ser traducido como "dicha" o en inglés bliss, así lo traduce por ejemplo Maniscalco Basile (20 I 5, 29).

${ }^{11}$ Un ejemplo de máquina que tiene el poder sin supervisión humana es La máquina se para de E. Forster, de 1909. En el relato los individuos han dejado su vida librada a los lineamientos de una máquina, la cual al comenzar a fallar lleva a la humanidad a la ruina sin que nadie pueda pararlo. En algún sentido aquí está el mismo conflicto que en Zamiatin, la tragedia de delegar la libertad en pos de la felicidad. 
un ser de carne y hueso. ${ }^{12}$ Es una especie de primer motor imprescindible para la maquinaria del Estado Único.

Es notable que en su anotación número 3, D-503, se refiera explícitamente a Kant para criticar la ética del siglo xx en relación a la ética científica del siglo xxx:

Y bien, ¿acaso no resulta ridículo? En nuestra sociedad, este problema matemático y moral lo resuelve en medio minuto cualquier número de diez ańos. En la suya, no podían hacerlo ni todos sus Kant juntos (porque ningún Kant consiguió crear un sistema de ética científica; es decir, un sistema basado en la sustracción, la adición, la división y la multiplicación) (Zamiatin 2008, 46)

En otras palabras, el conflicto entre, por un lado, ética y libertad y, por el otro, ciencia y felicidad, se zanja con una ética científica que se enfoca en la felicidad dejando de lado la libertad. Pero, ¿hasta qué punto puede hablarse de ética? La búsqueda de una ética científica, en el sentido universal y objetivo, ha sido un tópico de los problemas metaéticos del siglo xx. Una frase notable que permite dar cuenta de las limitaciones y al mismo tiempo de las promesas de ese enfoque puede rastrearse en la conferencia sobre ética que dictase Ludwig Wittgenstein en 1932 en Inglaterra, donde dice: “[...] si un hombre pudiera escribir un libro de ética que realmente fuera un libro de ética, este libro destruiría, como una explosión, todos los demás libros del mundo" (Wittgenstein i 990, 37).

Otra forma de pensar el problema de la ética científica podría ser a partir de la neuroética contemporánea, es decir, como intento de buscar en nuestra biología ese libro de ética que zanje todos los conflictos morales. ${ }^{13}$ Algo similar aparece en la anotación 2:

Y si es cierto que nuestros antepasados se entregaron a la danza en los momentos más inspirados de su vida (misterios religiosos, desfiles militares), entonces, esto no puede significar más que una cosa: el instinto de la no libertad es, desde tiempos inmemoriales, orgánicamente inherente al hombre (Zamiatin 2008, 36)

Aquí D-503 parece afirmar que los seres humanos estamos biológicamente estructurados para evitar la libertad en pos de la felicidad. No obstante, esa visión de la danza es justificable solo porque lo que ve danzar el protagonista son los ejes de una máquina y no un grupo de personas. En este segundo

${ }^{12}$ Por ejemplo, este pasaje: "[...] había una figura aparentemente hecha de metal a la que llamamos el Benefactor" (Zamiatin 2008, 84).

${ }^{13}$ Para una crítica de este enfoque, véase González Lagier (2017). 
caso, la improvisación todavía puede jugar un lugar que reivindique la libertad. Aun aceptando la interpretación de D-503, el inferir que de una práctica no libre se siga un instinto innato contrario a la libertad es, por lo menos, una generalización apresurada.

Otra forma de interpretar esa ética científica del Estado Único podría ser acercarla a algunos planteos contemporáneos de los defensores del mejoramiento humano (buman enhancement) por medios biotecnológicos. ${ }^{14}$ Por ejemplo, la intervención para extirpar la fantasía podría ser justificada como un mejoramiento cognitivo y moral. Esa "fantasictomía" llega en Nosotros al extremo de incluir también otras "mejoras" como ruedas. Sin embargo, hay dos problemas aquí. Primero, la fantasía o capacidad de imaginación parece ser algo que nos caracteriza como seres humanos desde hace miles de años. Por lo cual su extirpación — si eso fuera posible - más que parecer una mejora parece un empeoramiento disantrópico. ${ }^{15}$ Segundo, otra dificultad que encarna el planteo de una ética científica en los términos en los que es expuesto por D-503 viene dado por el carácter excepcional, leviatánico podría decirse, del Gran Benefactor. Este, como en las monarquías absolutas y en los totalitarismos más personalistas, parece ser la única excepción al determinismo de esa ética científica, él único que puede vivir libremente. Pero el giro de Nosotros, reproducido consciente o inconscientemente por Un mundo feliz de Huxley, viene dado por el hecho de que los esclavos de la maquinaria del Estado Único son felices - o al menos creen serlo- . El objetivo de la nave Integral consiste en exportar "la felicidad matemáticamente infalible", en cumplir el deber de obligar [a los venusinos y uranitas] a ser felices" (Zamiatin 2008, 33). La felicidad aquí no es una elección, una búsqueda personal, sino una obligación para la comunidad, lo que conduce directamente al segundo punto ético a analizar en Nosotros.

\subsection{Derechos del individuo vs. deberes para con la comunidad}

La novela, desde su título, remarca el predominio de la esfera colectiva sobre la individual. La igualación que busca garantizar la felicidad, por medio de la disolución del yo en el "nosotros", es llevada a todos sus extremos posibles. No solo no hay nombres, ni ropas que permitan distinguir a los individuos, ni prácticas u otros espacios de elección individual, de personalización del espacio vital, de individualización, sino que no hay derechos individuales de ningún (20I2)

${ }^{14} \mathrm{Al}$ respecto, véase la "máquina de Dios" imaginada por los filósofos J. Savulescu e I. Persson

${ }^{15}$ Sobre el concepto de "disantropía" como empeoramiento de la condición humana por medios biotecnológicos, véase Misseri (2016) y Bugajska (2019). 
tipo, solo obligaciones, sea de trabajar, dormir bien o mantenerse sanos para ser eficientes. Véase, por ejemplo, la anotación 20, donde D-503 considera que la fuente del derecho es la fuerza y a partir de allí afirma mediante una metáfora de ponderación:

[...] ahí lo tenemos: jos pesas en una balanza! En una hay un gramo y en la otra, una tonelada; en una estoy "yo" y en la otra, "nosotros", el Estado Único. ¿Es que no está claro? Permitir que el "yo" esté asistido por diversos derechos frente al Estado Único es exactamente lo mismo que permitir afirmar que un gramo pueda pesar lo mismo que una tonelada. De aquí se infiere la siguiente conclusión: la tonelada tiene derechos y el gramo deberes (Zamiatin 2008, 160-1)

En este ejemplo queda clara la obturación de todo posible derecho del individuo frente al Estado, a la entidad colectiva que esa institución busca preservar. Pero hay algo de falaz en la metáfora, porque si la tonelada está compuesta de un millón de gramos unidos, ¿entonces qué sería el Gran Benefactor? Es como si su peso estuviese fuera de la metáfora. Como si fuera el mero ejecutor de los intereses del colectivo, por lo cual podría ser interpretado — como se sugería más arriba - como un mero mecanismo y no como un sujeto con deseos. Pero si se lo interpreta como un sujeto más, sería el único gramo que pesa una tonelada, mientras que los demás gramos, incluso unidos, siempre pesarían un gramo. En términos más claros, Zamiatin sugiere que la desigualdad es notoria y no todos los individuos pesan igual, que solo el Gran Benefactor tiene peso, es decir, relevancia, y que todos los demás números son insignificantes.

Ya antes, en la anotación 7, D-503 se había valido de la retórica innatista para justificar la política avasalladora de los derechos individuales:

“¿Liberar?” Resulta asombroso comprobar hasta qué punto son activos los instintos criminales en la raza humana. Lo digo conscientemente: "criminales". La libertad y la criminalidad están tan indisolublemente ligadas entre sí [...] El único medio para librar al hombre de cometer crímenes es eximirle de la libertad (Zamiatin 2008, 70-1)

El razonamiento es sencillo: la criminalidad afecta al bienestar, hay criminalidad porque hay libertad, si se elimina la libertad no hay criminalidad, entonces, la anulación de la libertad incrementa el bienestar. A la libertad D-503 opone otros valores de la esfera de las máquinas "cotidianidad, reiteración y automaticidad" (Zamiatin 2008, 71). Del mismo modo que Kant satirizaba la "paz perpetua" como aquella de los cementerios (KANT 1998, 3), porque no hay 
interacción, lo mismo vale para esta felicidad del Estado Único, donde no hay acción libre. Donde no hay libertad para relacionarse con los otros, es dudoso que haya una genuina relación, o al menos una relación relevante. Es más bien una transacción que relaciones sustantivas como la amistad, por ejemplo.

En la anotación 11, D-503 se apoya no ya en el derecho, sino en el relato bíblico del Génesis y en cómo Adán y Eva habrían tomado la decisión, equivocada para ellos y para su progenie, sobre la base de tener libertad. Libertad es poder equivocarse, y en el Estado hiperracional el error es inaceptable porque amenazaría la dicha de los individuos: "A aquellos dos que entraron en el Paraíso se les ofreció elegir entre la felicidad sin libertad o la libertad sin felicidad. No se les dio una tercera opción. Y ellos, unos zoquetes, escogieron la libertad. Claro, así se comprende que luego, durante siglos, añoraran las cadenas" (Zamiatin 2008, 101). En este pasaje queda explícito cómo D-503 presenta a la libertad y a la felicidad como una dicotomía, o la una o la otra, pero no ambas. Son como dos fuerzas en conflicto, analizadas en el siguiente apartado.

\subsection{Energía vs. Entropia}

Es interesante que Zamiatin, en el marco de su distopía, haga referencia a la entropía, puesto que uno de sus autores más admirados $-\mathrm{H}$. G. Wells ${ }^{16}$ empleó la metáfora de la entropía para referirse al rol de la ética. Si la entropía es el mal, la ética es el esfuerzo humano por luchar contra ella mientras exista la vida. En el pensamiento de Wells, las fuerzas naturales parecen representar el mal y la destrucción, mientras que la fuerza de voluntad humana a través de sus artificios representa la oposición al fatalismo, entre otras cosas con la ayuda de la conciencia moral. Es en este sentido en el que pueden entenderse las palabras de I-330 cuando dice la famosa frase que tanto eco ha tenido en pensadores como Orwell (1946) o Voronsky (I988): “¿de qué última revolución me estás hablando? No existe ninguna revolución final, las revoluciones son también infinitas [como los números]. ¡La última! Eso es una palabra para niños, a quienes lo infinito les asusta, pues es imprescindible que por la noche duerman tranquilos" (ZамiaTin 2008, 226).

El mismo personaje, representante de los mefi[stofélicos], afirma: "hay dos fuerzas en el mundo: la entropía y la energía. Una tiende hacia el reposo beatífico y el feliz equilibrio, y la otra, hacia la destrucción del equilibrio, hacia el angustioso movimiento infinito" (ZAMiatin 2008, 216). Sobre dicha dicotomía puede establecerse una serie de oposiciones afines que se manifiestan especialmente en la anotación 30, pero que atraviesan toda la novela:

${ }^{16}$ Sobre la admiración de Zamiatin por Wells, véase el ensayo "H. G. Wells" (Zamiatin I970, 259-90) y Parrinder (I973). 


\begin{tabular}{|l|l|}
\hline Entropía & Energía \\
\hline Nosotros (felicidad) & Yo (libertad) \\
\hline Equilibrio (beatitud) & Desequilibrio (movimiento) \\
\hline Dios, cristianos, Estado único & Diablo, anticristianos, rebeldes mefi \\
\hline Racionalidad como limitación de lo infinito & Infinitud como irracionalidad \\
\hline Muerte o estado inorgánico & Vida \\
\hline Actitud madura solemne & Actitud infantil filosófica \\
\hline
\end{tabular}

Para D-503 la felicidad está en un "nosotros" racional y solemne, en el Estado Único como una nueva divinidad que equilibra a todos los individuos a favor de la felicidad colectiva y la eliminación de toda traza de libertad que pueda ponerla en peligro. En cambio, para I-330 el equilibrio buscado por el Estado Único implica la negación de la vida y de la actitud crítica ante ella. Si para los "números" acríticos la entropía tiene un valor positivo, para los mefi - como para Wells - tiene un valor negativo.

A modo de resumen de lo subrayado hasta ahora, puede decirse que la ética se manifiesta en la perspectiva de D-503 como aquello que no es completamente racional, en el sentido de que no siempre logra satisfacer del modo más eficiente las exigencias del bienestar colectivo. Por el contrario, la ética es, para el D-503 que ha superado la alienación y para los mefi, la reafirmación de la libertad del yo y de su propia vida en el marco de un universo infinito en constante movimiento. Esto hace pensar en la distinción wellsiana entre utopías estáticas y utopías dinámicas, es decir, entre aquellas que por presentarse como perfectas no admiten el cambio y aquellas que se presentan como perfectibles y permanecen abiertas a modificaciones y disensos (WeLLS 2000, 33). La ética es, en este segundo sentido, un esfuerzo activo, humano, consciente y libre por preservar la buena vida en un entorno que no siempre la posibilita.

\section{UNA INTERPRETACión KANTIANA DE LA POSTURA CRÍticA DE ZAMIATIN}

En la sección anterior se hizo un análisis del rol de la ética, y especialmente del contraste entre libertad y felicidad, reconstruyendo la perspectiva del personaje imaginado por Zamiatin a partir de sus anotaciones. En la sección actual se procurará ofrecer una interpretación de lo que podría haber querido 
transmitir Zamiatin con esa idea en su ficción. Generalmente, el carácter oblicuo de las distopías hace difícil derivar proposiciones positivas en torno a lo que piensa un autor distópico. Esto sucede porque de lo expuesto como negativo no necesariamente se sigue lo contrario. Por ejemplo, del hecho de que un mundo en el que la técnica sea vista como un arma para la anulación del individuo no se sigue que lo que sostiene el autor distópico deba ser necesariamente alguna forma de primitivismo neoludita. Una interpretación posible sería pensar que, en el caso de Zamiatin, este nos invita a volver a los espacios verdes y a vivir vidas más sencillas y libres; pero es más complicado que eso.

Asimismo, los aspectos artísticos y estéticos de la obra pueden ofrecer falsas pistas para interpretar la hipotética intención del autor. Críticos como Voronsky (1988) o Maniscalco Basile (2015) consideran que los aspectos estéticos tienen un rol preponderante en la obra de Zamiatin. Además, ciertos tópicos de Nosotros ya estaban presentes en otras obras del mismo autor, como Los Isleños, de 1917, texto en el que criticaba el modo de vida excesivamente regulado de los ingleses. Así pues, leer Nosotros solo como un ataque a la Rusia soviética sería también un error. No obstante, el objetivo de este trabajo no es extraer una interpretación integral de todo el texto, sino de aquello concerniente a la ética y, especialmente, de lo concerniente al problema de si es preferible la felicidad sin libertad o la libertad sin felicidad.

En este sentido, es notable que los únicos filósofos citados por Zamiatin en Nosotros sean Sócrates, por su aspecto, y Kant, por su contribución a la ética normativa. El filósofo alemán había manifestado en sus escritos el carácter secundario que tiene la felicidad en la ética con respecto a la libertad. En la obra de Zamiatin, Kant es contrastado con Taylor, quien según D-503 habría hecho más por la humanidad con sus principios de organización racional del trabajo que Kant con toda su obra filosófica.

\subsection{Libertad y felicidad en el pensamiento de Kant}

Para Kant, felicidad y libertad no están en conflicto. La felicidad es algo de lo que debemos buscar ser dignos, aunque no la consigamos y para ello necesitamos libertad. En la primera edición de su Crítica de la razón pura, de 1781, define a la felicidad como "la satisfacción de todas nuestras inclinaciones" y en el mismo párrafo distingue la ley práctica de la moral: "La ley práctica derivada del motivo de la felicidad la llamo pragmática (regla de prudencia). En cambio, la ley, si es que existe, que no posee otro motivo que la dignidad de ser feliz la llamo ley moral (ley ética)" (Kant i993, 631 A806). Por lo cual, a la pregunta iqué debo hacer? Kant responde taxativamente: "haz aquello mediante lo cual te haces digno de ser feliz" (1993, 632, A809). 
En cuanto a la libertad específicamente, hay que añadir que, si bien forma parte de las antinomias de la razón pura, lo cual acarrea que no sea posible para la razón establecer si somos libres o estamos determinados por las fuerzas de la naturaleza, ella misma es condición de posibilidad de la moral y que está presupuesta por ella. Si tiene sentido hablar de moral es porque, en términos prácticos, se postula que somos libres. Pero Kant no se queda ahí. En su comentario sobre la República de Platón vertido en la segunda edición de Crítica de la razón pura, de 1787, dice que:

una constitución que promueva la mayor libertad humana de acuerdo con leyes que hagan que la libertad de cada uno sea compatible con la de los demás (no una constitución que promueva la mayor felicidad, pues ésta se seguirá por sí sola), es, como mínimo, una idea necesaria... (KANT 1993, 311-2, B373)

En otras palabras, Kant asegura que la libertad es más importante que la felicidad, que debemos orientar nuestras instituciones políticas para que garanticen la libertad, y que es esto lo que produciría la felicidad. Justo lo contrario de lo que sostiene la retórica del Estado Único en Nosotros. Para el filósofo de Königsberg si se da un conflicto entre la libertad y la felicidad no caben dudas sobre qué salvar y qué sacrificar. Mientras la felicidad es incierta, debido a su carácter subjetivo, la libertad es una condición de posibilidad para obtener algo más valioso que la felicidad a secas: la dignidad de ser feliz, es decir, el resultado de haber obrado moralmente y no por la mera inclinación. Esto no quiere decir que Kant considere que la felicidad deba ser descartada. Reconoce que es natural en nosotros buscarla, si bien añade que el deber moral la antecede. La diferencia entre la felicidad y la dignidad de ser feliz es que la primera depende de la naturaleza y la segunda de nuestra libertad. Como dice en sus Trabajos preparatorios de "Teoría y Práctica": "La felicidad es algo que la Naturaleza puede otorgar. La consciencia de que se es digno de ella solo puede proporcionarla la razón mediante la libertad...” (KANT 2013, 266).

Quizás estas ideas hayan llegado a Zamiatin, ya sea por su lectura directa o porque formaban parte del ambiente intelectual en el que se formó. La filosofía alemana tuvo un fuerte influjo en el pensamiento ruso de los siglos XIX y Xx, junto con la francesa y la corriente eslavófila - la cual mantuvo una relación ambigua con Occidente-. En 1823, ya la sociedad secreta Lyubomudrya, término eslavófilo equivalente a "filosofía", se interesaba entre otros pensadores por Kant (Jeu i 98 I, 255). Y en 1867, Mijaíl I. Vladislavlev traducía al ruso la Crítica de la razón pura y, en 1897, N. M. Sokolov hizo lo mismo con la Crítica de la razón práctica (KRYshtop 20I6). Por eso no extraña que Kant aparezca mencionado en la obra de Zamiatin en más de una oportunidad. En el escrito 
sobre el científico alemán Julius Robert von Meyer, a quien atribuye el mismo espíritu herético que él comparte, Zamiatin escribe que los "gobernadores de las mentes de los jóvenes alemanes de entonces eran los líderes de la filosofía abstracta y especulativa: Kant, Schelling, Hegel" (Zamiatin 2003в, 438). También hay menciones posteriores en las que traza un vínculo entre el pensamiento kantiano y el simbolismo literario ruso, tal es el caso de sus ensayos "La nueva prosa rusa" (I970, I05 y 2004, 138) y "Sobre el sintetismo" ( 1970,85 y 2004, 167), ${ }^{17}$ o en sus notas "Sobre el lenguaje" (20 I I, 355) y "Sobre el futurismo" (201 I 387). En todos ellos, se da cuenta del influjo del pensamiento de Kant, tanto en la ciencia como en la literatura. Es cierto que, en lo literario, para Zamiatin el simbolismo de influencia kantiana - en tanto que negación del realismo y el naturalismo de autores como Tolstoi o Zolase veía superado por el neorrealismo o "sintetismo" — en tanto negación de la negación - Pero, la crítica de Zamiatin a Kant no llega a su teoría ética, sino al influjo literario de su teoría del conocimiento.

\subsection{Una interpretación del conflicto libertadlfelicidad en Zamiatin}

Como ya se mencionó al principio de esta sección el carácter oblicuo de las distopías dificulta la tarea interpretativa. La postura de Zamiatin, ¿es la de D-503 o la de los mefi? ¿Ambas son mutuamente conciliables? ¿Cree Zamiatin en la compatibilidad entre libertad y felicidad? En varias de sus obras, Zamiatin empleó la sátira para atacar ciertos valores establecidos, primero contra la vida provinciana rusa en Una historia de provincias, luego contra la vida hiperregulada de los ingleses en Los isleños y finalmente contra la poesía estatal rusa y el naciente Estado soviético en Nosotros y otras obras. Pareciera que en la dualidad presentada entre energía y entropía Zamiatin se sitúa del lado de la energía, la revolución permanente, el inconformismo y sobre todas las cosas la libertad creadora.

Kern $(1988,20)$ y Maniscalco Basile $(2015,26)$ coinciden en que el credo de Zamiatin lo constituye su artículo "Scythians?", de 1918. El escita sería aquel nómada cuyas "más preciadas cosas son su libertad, su soledad, su caballo y la amplitud de la estepa" (Zamyatin i970, 21). Hay buenas razones, derivadas de la biografía de Zamiatin, para determinar que situaba su libertad artística por encima de su bienestar. Recordemos que fue apresado varias veces por sus escritos, ya sea por el zarismo, ya por los soviéticos, y que murió en el

${ }^{17}$ Las referencias de estos dos ensayos aluden al volumen 3 de las obras completas de $\mathrm{Za}$ miatin en su idioma original. Para una traducción al inglés, véase (ZAMYATIN I970, 105 y 167). De la biografía de Meyer y de las notas sobre lenguaje y futurismo no se ha logrado encontrar traducción al español ni al inglés al momento de la escritura de este artículo. 
exilio, pobre y desprestigiado en su propia tierra. Sin embargo, ¿quiere decir esto que Zamiatin consideraba que el conflicto entre libertad y felicidad solo podía zanjarse a partir de una de ambas? Por las menciones a Kant, creemos que no obligatoriamente. Así como Kant consideraba que la felicidad era una motivación ética, pero no necesariamente un fin alcanzable, algo similar ocurre con Zamiatin. Su lucha por su libertad creativa busca hacerlo feliz, aunque esto no ocurra.

No obstante, uno podría preguntarse si este es realmente un problema ético. La principal crítica que le hicieron las tempranas lecturas soviéticas fue que el planteo estético de Zamiatin era virtuoso estilísticamente, pero individualista y mezquino en su persecución del mero arte por el arte, sin tener en cuenta el compromiso político. Ahora bien, ¿es esta acusación cierta? Aquí se considera que no, y para ello se busca apoyo en Wells. La visión del artista comprometido aquí corre paralela al compromiso con la crítica permanente, sin importar si se critica a los propios camaradas. Tal cosa como una literatura oficial parece atentar, para Zamiatin, no solo contra los criterios estéticos, sino contra la misma idea de bienestar social al impedir la autocrítica. No hay una revolución que alcance la utopía definitiva, sino que la mejora debe ser permanente, lo cual no implica que no pueda haber progresos sustanciales en el bienestar de todos los individuos impulsados por revoluciones. Implica que no existe un punto y final. Y no existe por las características de la propia naturaleza humana. No precisamente por la envidia, como dice D-503 en Nosotros, por mucho que esta pueda jugar un rol importante, sino por la finitud y vulnerabilidad características del ser humano. Toda sociedad encuentra un conflicto entre el carácter ilimitado de los deseos de todos sus individuos y el carácter limitado de los recursos de que dispone. Si la utopía será algo, será, por mor de esas características humanas, cambiante, dinámica y libre.

\subsection{Algunos argumentos en contra del conflicto libertad/felicidad entendido como dicotomía}

Hay varias razones para considerar que la libertad y la felicidad son compatibles. No obstante, como se trata de términos polisémicos es importante especificar la semiosis de los mismos. Tanto la libertad como la felicidad pueden ser graduables. Por tanto, es pensable un cierto grado de libertad compatible con un cierto grado de felicidad. En los pasajes citados de Dostoievski, la felicidad se confunde con la satisfacción de las necesidades básicas, lo que el Gran Inquisidor llama "el pan". No obstante, aun admitiendo que ese pudiera ser un grado de felicidad, seguramente sería uno de los más bajos. Asimismo, si se sacrifica la libertad en su totalidad por la satisfacción de las necesidades 
básicas uno se encuentra en un estado de esclavitud. Alguien podría objetar que esa persona aún tiene un grado mínimo de libertad: puede elegir someterse o morir. Entonces podría pensarse que libertad y felicidad son compatibles al menos en estos mínimos. Pero cuando hablamos de libertad y felicidad en su sentido corriente estamos pensando en algo más que la posibilidad de suicidarse o de satisfacer las necesidades elementales.

Desde Aristóteles en adelante, se considera que una serie de bienes externos mínimos constituyen una condición de posibilidad de la felicidad y podría añadirse que ese mínimo también es condición de posibilidad de la libertad en su sentido positivo o material. Puedo ser libre de estudiar, pero si el hambre no me deja concentrarme para leer, de poco me vale esa libertad. Entonces, ¿qué significan libertad y felicidad en ese sentido corriente? La libertad tiene que ver con la autonomía, con la capacidad de decidir y revisar periódicamente el propio plan de vida, de modo que este me permita desarrollar ciertas capacidades o, en términos neoaristotélicos, que me permita "florecer". En cambio, la felicidad podría ser definida como una combinación entre un sentimiento positivo, la satisfacción de necesidades básicas y el cumplimiento del plan de vida en su mayor parte. En este sentido, la libertad se vuelve condición de posibilidad de la felicidad; uno es feliz porque puede desarrollar sus capacidades voluntariamente. Es por eso que frases de Nosotros como "obligarles a ser felices" suenan contraintuitivas y pueden ser vistas como una crítica anticipada a la actual "industria de la felicidad".

Algunos podrían pensar que este problema podría ser analizado a través de la máquina de experiencias de Nozick (1999, 42-5). Este filósofo emplea un experimento mental para procurar probar que no solo deseamos tener bienestar psicológico, sino que queremos que ese bienestar sea real. Para eso idea una máquina en la cual olvidaríamos que estamos en ella una vez entrar y tendríamos solo experiencias positivas. Para Nozick la intuición es que aun sabiendo que la máquina no puede fallar y que podríamos tener contacto con nuestros seres queridos hay algo en nosotros que no nos permitiría abandonar nuestra libertad a cambio de esa felicidad sintética por más verosímil que resulte. En los últimos tiempos la filosofía experimental se ha ocupado de este problema contradiciendo la intuición de Nozick o al menos mostrando que el sesgo cambia según cómo se rediseñe el experimento (De Brigard 20 Io; Weijers 20I4). Pero hay dos aspectos que permiten preservar el rechazo de la máquina de experiencias. La primera atiende a la primera formulación de la misma: uno quiere tener intercambio con otros, la felicidad se puede compartir, no basta con introducirse en algo parecido a Matrix. Por ello, Nozick reformula el ejemplo en el mismo libro, aunque no es la versión más estudiada. Pero aun así hay una buena razón para rechazar trocar la libertad por esa felicidad 
mecánica, y es que la experiencia parece enseñarnos que incluso las máquinas más sofisticadas fallan. Forster muestra en la distopía La máquina se para que si cedemos nuestra libertad y la máquina falla, el daño podría ser todavía mayor: la extinción de la humanidad.

No obstante lo anterior, es cierto que la satisfacción del propio plan de vida puede no ser garantía de felicidad, especialmente por la parte emocionalsentimental de la felicidad. Puede que cumplir los propios deseos no sea fuente suficiente de felicidad, pero no tener la libertad de hacerlo es fuente segura de infelicidad. Al mismo tiempo, ser libre para cumplir el propio plan de vida y lograr cumplirlo tiene un valor agregado al hecho de cumplirlo por azar o por voluntad de otro. Ese valor agregado es, probablemente, un aspecto emocional, pero no algo a ignorar. Las emociones afectan nuestra autopercepción.

Todavía nos queda la pregunta de si se puede ser feliz sin ser libre. La respuesta más inmediata nos lleva de nuevo a la graduabilidad: nadie es totalmente feliz ni totalmente libre. Pero, ¿puede concebirse el caso de una persona que carezca por completo delibertad y que sea feliz? En un sentido menos complejo que el de felicidad, que hemos llamado corriente, podría decirse que sí. Los nińos tienen un grado menor de libertad, pero pese a ello pueden tener sus necesidades satisfechas y un conjunto de sentimientos positivos en torno a su situación. Sin embargo, ese es un caso especial y Zamiatin nos plantea el problema en el contexto de los adultos. Quizá la respuesta esté nuevamente en Kant. Querer vivir como un nińo siendo adulto es no osar saber, no abrazar la Ilustración que es precisamente "el abandono por parte del hombre de una minoría de edad cuyo responsable es él mismo" (Kant 2013, 87).

\section{Conclusión}

En este trabajo se partió de una definición de distopía como narración de una sociedad subóptima con la intención de poner de manifiesto los aspectos a mejorar de las sociedades del presente. Como es el caso del Estado Único de la novela Nosotros de Zamiatin, el problema no es solo político sino también ético. Para ello se rastreó en la novela del escritor ruso la visión que el protagonista, D-503, desglosa en sus notas en torno a ciertos problemas ético-normativos en los cuales las dimensiones política, jurídica y religiosa no están ausentes.

Tras ese relevamiento de la visión de la ética se subrayó un problema que atraviesa toda la novela: el conflicto entre la libertad y la felicidad expuesto como una dicotomía. En el Estado Único el conflicto se resuelve a favor de la felicidad colectiva, a costa de la pérdida de la libertad individual y de la anulación de la conciencia moral y de otros aspectos clave del ser humano. 
Se ofreció una interpretación de la postura de Zamiatin según la cual este seguiría a Kant en darle prioridad a la libertad por sobre la felicidad. Algo destacable en tanto que la libertad es condición de posibilidad de la ética. Se defendió también una especial visión del intelectual comprometido con la crítica constante y la mejora continua que asociamos a la influencia de Wells en el pensamiento del escritor ruso.

Finalmente, se ofreció un análisis propio de la compatibilidad de la libertad y felicidad en un sentido mínimo y en un sentido corriente, mostrando que no solo la libertad y la felicidad son compatibles, sino que en su sentido corriente un grado aceptable de libertad es necesario para un grado aceptable de felicidad. 


\section{BIBLIOGRAFÍA}

Adorno, T. I962, "Aldous Huxley y la utopía”, Prismas: crítica de la cultura y de la sociedad, Barcelona: Ariel, 99-125.

Bugajska, A. 2019, Engineering Youth: The Evantropian Project in Young Adult Dystopias, Cracovia: Ignatianum.

Claeys, G. 20 17, Dystopia: A Natural History, Oxford: Oxford University Press.

Curtis, J. A. E. 2013, The Englishman from Lebedian': A Life of Evgeny Zamiatin, Boston: Academic Studies Press.

De Brigard, F. 20io, "If you like it, does it matter if it's real?", Philosophical Psychology, 23: 1, 43-57. Doi: 10.1080/09515080903532290

Dostoiewski, F. I930, Los hermanos Karamazov, A. Nadal (trad.), Madrid: Airon.

Forster, E. 20i6, La máquina se para, J. Rodríguez Hidalgo (trad.), Madrid: Ediciones del Salmón.

González Lagier, D. 2017, A la sombra de Hume: un balance crítico del intento de la neuroética de fundamentar la moral, Madrid: Marcial Pons.

Huxley, A. I999, Un mundo feliz, R. Hernández (trad.), Madrid: Unidad.

Jerome, J. K. 20 i 8 [1891], La nueva utopía, J. González-Torres Domingo (trad.), Madrid: Unión Editorial.

Jeu, B. I98 I, "La filosofía rusa”, Las filosofias nacionales: siglos XIX y XX, BeLavaL, I. (ed.), Madrid: Siglo xxi.

Kant, I. 20I3, ¿Qué es la Ilustración? Y otros escritos de ética, politica y filosofía de la historia, R. R. Aramayo (ed.), Madrid: Alianza.

Kant, I. I998, Sobre la paz perpetua, J. Abellán (trad.), Madrid: Tecnos.

Kant, I. I993, Crítica de la razón pura, P. Ribas (trad.), Madrid: Alfaguara.

Kern, G. (ed.) I988, Zamyatin's We: A Collection of Critical Essays, Ann Arbor: Ardis.

Kiselova Savrasova, V. y Marín Hernández, D. 2015, "La traducción y recepción en España de Nosotros, de Evgueni Ivánovich Zamiatin”, Sendebar (26): 167-93.

Kryshtop, L. 2016, "The reception of Kant in Russia”, Con-Textos Kantianos: International Journal of Philosophy, 4: 56-69. Doi: 10.5281/zenodo.163989

MÁlishev, M. I997, "Dostoievski y Kant: antinomia de la libertad y la felicidad”, Ciencia ergo sum 4(3): 333-40.

Maniscalco Basile, G. 20 i 5, "The Algebra of Happiness: Yevgeny Zamyatin's We", Quaestio Rossica (4): 19-39. https://doi.org/10.15826/qr.2015.4.124

Misseri, L. E. 2016, "Evantropia and Dysantropia: A Possible New Stage in the History of Utopias”, Olkusz, K., M. KŁosiński y K. M. Maj, More After More: Essays Commemorating the Five-Hundredth Anniversary of Thomas More's Utopia. Cracovia: FactaFicta, 26-42. 
Moylan, T. 2000, Scraps of the Untainted Sky: Science Fiction, Utopia, Dystopia, Boulder: Westview Press.

NozIcK, R. 1999, Anarchy, State, and Utopia, Oxford y Cambridge (US): Blackwell. Orwell, G. 1946, "Review of Zamyatin's We", periódico Tribune, Londres. Disponible en https://orwell.ru/library/reviews/zamyatin/english/e_zamy

Orwell, G. 2003, 1984, R. Vázquez Mora (trad.), Barcelona: Destino.

Parrinder, P. I973, "Imagining the Future: Zamyatin and Wells". ScienceFictionStudies, Vol. 1, No. 1: 17-26.

Platón 2004, República, A. Camarero (trad.), Buenos Aires: Eudeba.

Savulescu, J. y Persson, I. 201 2, "Moral Enhancement, Freedom and the God Machine", The Monist, 95(3): 399-421.

Shrolovsky, V. 1988, "Evgeny Zamyatin's Ceiling", Zamyatin's We: A Collection of Critical Essays, Kern, G. (ed.), Ann Arbor: Ardis, 49-50.

Trousson, R. I995, Historia de la literatura utópica: viajes a paises inexistentes, C. Manzano (trad.), Barcelona: Península.

Voronsky, A. 1988, "Evgeny Zamyatin", Zamyatin's We: A Collection of Critical Essays, Kern, G. (ed.), Ann Arbor: Ardis, 25-48.

Wegner, P. E. 1993, "On Zamyatin's We: A Critical Map of Utopia’s 'Possible Worlds", Utopian Studies, Vol. 4, No. 2: 94-116.

WeIjers, D. 20I4, "Nozick's experience machine is dead, long live the experience machine!", Philosophical Psychology, 27, 4: 513-35. Doi: 10.1080/09515089.2012.757889

Wells, H. G. 2000 [1905], Una utopia moderna, J. Sánchez Rottner (trad.), México: Océano.

Wittgenstein, L. i990, Conferencia sobre ética, Barcelona: Paidós.

Zamiatin, E. 1968, La pulga, A. Fierro (trad.), AA.VV., Teatro cómico soviético, Madrid, Aguilar, 58-115.

Zamiatin, E. 2008, Nosotros, S. Hernández-Ranera (trad.), Madrid: Akal.

Zamyatin, Y. 1970, A Soviet Heretic: Essays by Yevgeny Zamyatin, M. Ginsburg (trad.), Chicago y Londres: The University of Chicago Press.

ЗАМЯТИН, Е. И. [Zamiatin, E. I.] 2003А, СОБРАНИЕСОчИНЕНИЙ 1: УЕЗДНОЕ [Obras completas 1: Cuento de provincias/Úyezd], Moscú, Русскаякнига.

ЗАмЯтин, Е. И. [Zamiatin, E. I.] 2003в, СобРАниеСочинениЙ 2: РуСь [Obras completas 2: Rus'], Moscú, РусскаякНИГА.

ЗАмЯТИН, Е. И. [Zamiatin, Е. I.] 2004, СоБРАНИЕСОчИНЕНИЙ 3: ЛИЦА [Obras completas 3: Personas], Moscú, Русскаякнига.

ЗАмЯтИН, Е. И.[Zamiatin, Е. I.] 20го, СОБРАНИЕСочИНЕНИЙ 4: БЕСЕДЫЕРЕТИКА [Obras completas 4: Conversaciones de un hereje], Мoscú, РусСКАЯкНИГА.

ЗАМЯТИН,Е.И. [Zamiatin,E.І.] 20 I I, СОБРАНИЕСОчинЕНИй 5:ТРУДНОЕМАСТЕРСТВО [Obras completas 5: Difícil Maestría], Moscú, РусскаякнигА. 
